\title{
Conflicto y poder en las investigaciones socioambientales Un necesario contexto teórico
}

\author{
Jorge Federico Eufracio Jaramillo*
}

Recepción: 11 de septiembre de 2017 / Aceptación: 6 de febrero de 2018

Resumen El presente artículo tiene como objetivo la creación de un marco teórico, conceptual y epistemológico general para el estudio de conflictos socioambientales. En este sentido, se resalta el valor analítico de conceptos como conflicto, poder y territorio, que permiten entender las dimensiones sociales, políticas, económicas, espaciales, culturales y simbólicas de los mencionados fenómenos sociales. El texto no solo desea cumplir con las metas estrictamente académicas, sino denunciar las asimetrías, desigualdades, agravios y estructuras de poder que están detrás de los daños sistemáticos al medioambiente. PALABRAS CLAVE: conflicto, medioambiente, poder, territorio, territorialidad.

\section{Conflict and power in socio-environmental research A needed theoretical context}

Abstract The present article aims to provide a theoretical, conceptual and epistemological framework for the study of environmental conflicts. Here the analytical value of concepts such as conflict, power and territory is stressed, since these are what allow the social, political, economic, spatial, cultural and symbolic dimensions of this kind of social phenomenon to be understood. Finally, while following academic guidelines, the text also hopes to denounce, at least in a general sense, some of the asymmetries, inequalities, grievances and power structures that lie behind much of the damage to the environment. KEYWORDS: conflict, environment, power, territory, territoriality.

* Profesor investigador de El Colegio de Jalisco, Jalisco, México. jorge.eufracio@coljal.edu.mx 
Introducción

1 presente artículo tiene como principal objetivo ofrecer un marco teórico conceptual de referencia, un necesario punto de partida que permita plantear y entender los fundamentos académicos centrales que hoy en día vinculan a los estudios sobre conflictos socioambientales. En concreto, se desea señalar los debates básicos que, en forma general, circunscriben la actualidad de dichas investigaciones, pero concentrándose de manera particular en aquellas reflexiones que ayuden a entender la actualidad de América Latina en la materia. Siguiendo tales avances reflexivos, se mostrarán, desde una perspectiva predominantemente sociológica, algunos de los principales rasgos históricos y estructurales comunes a los países latinoamericanos con la intención de explicitar la importancia de dichas acciones colectivas en favor del medioambiente. Lo anterior con el fin de reafirmar su trascendencia no solo científica sino también humana, en tanto que revelan la profundidad de las actuales externalidades y las posibles consecuencias del deterioro de la naturaleza por la mano del hombre.

Para cumplir con lo anterior, el texto partirá de una discusión acerca del concepto de conflicto: su significado, su importancia epistemológica para las ciencias sociales y su vigencia para entender procesos reales. Después se especificarán las principales capacidades analíticas que tiene el concepto cuando es aplicado al entendimiento de las actuales tribulaciones que sufre el medioambiente considerando como elemento central la intervención o confrontación de actores concretos. Al respecto, se ofrecerán algunos de los debates que circundan la definición de los conflictos socioambientales y, a su vez, las posibilidades brindadas, a partir de su uso, para entender que los actuales patrones de degradación intensiva de la naturaleza no solo responden a dinámicas y actores locales, sino también a tendencias estructurales/globales y a intereses transnacionales que son característicos del estado de profundización prevaleciente en el neoliberalismo. Proceso que se ha traducido, como se reflexionará en el cuerpo del texto, en nuevas o acentuadas formas de explotación del medio natural, así como de despojo de las comunidades.

Siguiendo tal argumento central, el presente artículo también establecerá, en uno de sus apartados, los necesarios puntos de contacto entre los conceptos de conflicto socioambiental, poder y territorio. Esto para demostrar que la variable económica no es la única que explica el origen, el desarrollo y las externalidades del deterioro del medioambiente, sino también las formas de dominación, las jerarquías actuantes a nivel global y la solidificación de las asimetrías en todos los niveles. Asimismo, que el territorio no debe verse como una simple porción de la superficie terrestre, sino también como una dimensión de lo social en la cual se producen y reproducen las relaciones políticas, las estructuras ideológicas y las 
tramas simbólico-culturales que entrañan la vivencia ambiental cotidiana y sus sentidos atribuidos.

En diálogo con lo anterior, se desea revelar que el cúmulo de condiciones adversas y sus implicaciones han provocado diversas respuestas entre la población directamente afectada o entre aquellos grupos, asociaciones, movimientos o colectivos que se asumen apeladas debido, por un lado, a una conciencia global de que, en lo referente al medio ambiente, el deterioro o la sobreexplotación en cualquier sitio afecta a todos o, por otro lado, a un compromiso de participación política, de resistencia u oposición en contra de los tajantes aprovechamientos fomentados por la economía de libre mercado y la retracción o repliegue del Estado ante tales embates internacionales. En esta tesitura, se considera que el conflicto y su traducción en movilización social, tal como se argumenta en el texto, no debe ser visto, por lo menos no a priori, como un fenómeno social negativo, sino más bien como una fuerza que puede impulsar transformaciones positivas, en especial cuando la continuidad de la vida humana está en juego.

Para concluir con este apartado introductorio, vale la pena recalcar que es deseo de este escrito aportar concretamente a la ampliación de los debates teóricos y epistemológicos acerca de los conflictos socioambientales, ya que se considera que el fortalecimiento de dichas bases es elemental para construir análisis más profundos y más útiles para entender lo que estos fenómenos entrañan, sus diversas aristas y la complejidad de sus implicaciones sociales, simbólicas, económicas, políticas y territoriales. No obstante, también se pretende diseminar un enfoque ideológico comprometido con la lucha por una sociedad más justa, una perspectiva crítica hacia una realidad imperante e incluso una posición de denuncia ante los grandes efectos adversos provocados por las actuales formas, en su mayoría verticales, de apropiación, dominio, extracción, acaparamiento o explotación del medioambiente. Asimismo, la inclusión en un diálogo más abierto dentro de la academia, pues se espera que lo expresado en él promueva la formación de perspectivas críticas y mayor compromiso social ante lo que ocurre a nuestro alrededor.

El punto de partida: el conflicto

Según Chantal Mouffe una de las principales herencias del liberalismo, y más específicamente de la democracia liberal, es una estructura de pensamiento, aún muy común entre investigadores y teóricos sociales, que no permite la asimilación de la diferencia, el antagonismo y la confrontación en las relaciones sociales, toda vez que la principal aspiración humana, según esta corriente ideológica, es la superación de las pasiones mediante la razón (Mouffe, 1999: 11-12). De esta manera, el conflicto es solo una etapa pasajera que, a partir 
del desarrollo del conocimiento científico y de las capacidades individuales, será trascendida y sustituida por un orden en donde las contradicciones no tendrán cabida. Sin embargo, esta postura, más allá de las buenas intenciones de tal escuela de pensamiento, traza un mundo irreal al negar una condición esencial de la vida en sociedad (Silva, 2008: 29) pues, tal como lo explica Mouffe, la dimensión de antagonismo, hostilidad o discrepancia existe en todas las relaciones humanas (Mouffe, 1999: 14-16).

Debido a lo anterior, el concepto de conflicto refiere, según estos argumentos, a un aspecto intrínseco de lo humano, una de las formas más activas de socialización (Stamm y Aliste, 2014: 69), una constante histórica e incluso un motor de los cambios sociales. En efecto, de acuerdo con la llamada teoría de los conflictos (Molina y Muñoz, 2004: 146) el mencionado concepto no representa per se una fase de anomalía o disfuncionalidad de las sociedades, ni tampoco, en forma generalizada, un momento peligroso (antesala de la violencia), malo o negativo (Silva, 2008: 29). Por el contrario, la mencionada teoría estipula que el conflicto, como modalidad de relación entre grupos o individuos (Stamm y Aliste, 2014: 69), puede ser un factor de regulación social, un facilitador de la cohesión, un refuerzo para la identidad de un grupo o un estímulo para la creatividad o la innovación (Stamm y Aliste, 2014: 69). Es así que el mencionado concepto se utiliza hoy, desde muy diversas perspectivas, para entender «las redes de relaciones, el papel de los valores y las ideas, las conductas y comportamientos, la distribución del poder y los mecanismos de cambio» (Molina y Muñoz, 2004: 146).

Todos los argumentos anteriores contienen serias implicaciones teóricas y metodológicas, pero primeramente epistemológicas. Esto porque las características del concepto de conflicto enunciadas entrañan una forma diferente de entender el desenvolvimiento del mundo social, el cual estaría dirigido no hacia la búsqueda de un orden supremo e inerte que revele, después de la abolición de todas las contradicciones, el advenimiento de una justicia absoluta (tal como lo sostiene la idea de progreso), sino hacia la naturalización del antagonismo como consustancial a lo social y por ello, en sus múltiples dimensiones empíricas, como evidencia irrefutable de su constante movimiento y tendencia al cambio. En otras palabras, la primera posición epistemológica entiende al equilibrio como una línea recta (estable o inmóvil) y al conflicto como su antítesis, mientras que el segundo concibe al equilibrio como una línea oscilante (dinámica o variable) y al conflicto como una de las energías que la impulsa.

La segunda de estas perspectivas epistemológicas es justo la que fundamenta a la mencionada teoría del conflicto y de la cual se han desprendido varios efectos positivos para la investigación social en general. Uno de los principales es que se ha revalorado la necesidad 
y actualidad del concepto para estudiar diversos fenómenos, así como su potencial analítico para explicarlos como procesos multifacéticos, multivariados y complejos. Al respecto, dicha propuesta contempla como elemento central la posición relativa de los actores en disputa, ya que es la contraposición de sus intereses, valores, prácticas y formas de ver el mundo lo que brinda a cada situación de antagonismo sus específicos matices, pero también su profundidad sociológica. De tal forma que, bajo este enfoque de la teoría del conflicto, el concepto se ha convertido en una herramienta sumamente útil, incluso transdisciplinar, para plantear una vía diferente de análisis respecto a una de las grandes preocupaciones de las ciencias sociales: cómo explicar el cambio social. Esto considerando que el conflicto representa, en efecto, un proceso con naturales capacidades de transformación.

No obstante, dada la pluralidad y vasta aplicabilidad del concepto de conflicto, este ha sido definido desde muchas perspectivas, dependiendo del enfoque y los objetivos de cada investigación. Aun así es posible encontrar algunas características fundamentales que, en general, se conservan en la gran mayoría de las definiciones, a decir, la existencia de partes (actores), motivaciones (o intereses) y relaciones de poder (Guerrero, 1999: 38). Considerando tales elementos, se destaca la siguiente definición, ya que no solo los contempla, sino que los vincula resaltando su carácter relacional y público; un conjunto de propiedades que, como se verá más adelante, son esenciales para plantear la ramificación socioambiental del concepto:

Es una acción colectiva, es decir una situación que implica la contraposición de intereses, derechos, perspectivas, racionalidades o lógicas. Es un hecho social objetivo que surge de discrepancias entre sujetos — individuos, clases o etnias — en torno a la percepción y la comprensión de la realidad por cada uno, en su manera de figurarla o reinventarla. Es producto de una concepción del mundo, de la naturaleza y de los hombres, de la forma en que estos últimos se relacionan, se organizan y entran en oposición (Fontaine, 2003a: 516).

Por supuesto que la anterior definición, aun cuando tiene claridad, establece una base muy general para plantear los elementos constitutivos de un conflicto; un necesario punto de partida, pero que no está elaborado para captar y evidenciar aquellos elementos más finos o específicos. Al respecto, el concepto de conflicto ha sido relacionado con una multiplicidad de apellidos para precisar su aplicación a un determinado campo de relaciones sociales. Así, han surgido, por un lado, nuevos conceptos como: conflicto cultural, conflicto histórico, conflicto de facciones, conflicto inducido o conflicto extremo que desean especificar la esencia del fenómeno estudiado. Y, por otro lado, un conjunto de oposiciones binarias como conflictos reales o instrumentales versus conflictos irreales o expresivos, conflictos latentes versus conflictos manifiestos, conflictos institucionalizados o no institucio- 
nalizados, entre otros, con el fin de señalar la intensidad de la confrontación de intereses (Fontaine, 2003b: 27-28). Sin embargo, y más allá de la aplicabilidad de los mismos, lo que estos desean establecer es una diferenciación de los actores inmiscuidos, de los vínculos entre ellos, de las estructuras sociales actuantes, de los diferenciales de poder, de las identidades en juego y de los objetos de confrontación (Munévar, González y Henao, 2016: 166).

\section{La dimensión (socio)ambiental del conflicto}

Siguiendo el argumento anterior, es necesario especificar, en aras de cumplir con los objetivos planteados para este artículo, cuáles son aquellas cualidades o particularidades de los conflictos que ocurren en relación con el medioambiente. Por principio, el acuerdo general es que este tipo de conflictos tienen un claro origen en la intrínseca relación entre el hombre y la naturaleza. Sin embargo, dada la complejidad del tema y su heterogeneidad empírica, existen varios posicionamientos al respecto con sus respectivas propuestas teóricas. De entre ellas han surgido diferentes conceptos (por ejemplo, conflictos inducidos por el ambiente, ecológico-distributivos o de contenido ambiental) ${ }^{1}$ y de los cuales se desprenden los debates acerca de dos diferencias teóricas importantes: entre conflictos o problemas socioambientales, y entre conflictos ambientales o socioambientales.

Con respecto a la primera de ellas, conflictos y problemas no son sinónimos y no siempre están interconectados entre sí. Al respecto, existen problemas ambientales, como la contaminación atmosférica o la erosión de los suelos, que no en todos los casos implican una interacción entre dos o más personas o, mejor dicho, un estado de confrontación entre actores. De esta manera, y de acuerdo con tales debates teóricos, estaremos frente a un conflicto ambiental cuando existe una conciencia del agravio y se actúa en consecuencia» (Paz y Risdell, 2014: 6).

Por otra parte, de acuerdo con la segunda discusión, los conflictos ambientales son aquellos que refieren a un daño ocurrido a los recursos naturales y que es interpelado por actores exógenos, como lo serían las organizaciones ambientalistas o activistas. Mientras que, por otro lado, los socioambientales refieren a aquellos casos en los cuales las comunidades directamente afectadas se involucran para defenderse de los diferentes impactos generados por un determinado proyecto (Walter, 2009: 1). Es evidente que, en este caso, la línea divisoria entre ambos conceptos es muy delgada, opaca e incluso superficial, por lo que ha recibido algunas críticas. La más importante es que no puede existir un conflicto

${ }^{1}$ Para mayores referencias sobre tales conceptos, véase Munévar, González y Henao (2016). 
ambiental sin dimensión social (Fontaine, 2003b: 21), por lo que no se entiende por qué los actores exógenos ocuparían una categoría diferente.

No obstante, más allá de dichas críticas, la divergencia analítica planteada por ambos conceptos indica la existencia de diferentes concepciones acerca de la complejidad de las relaciones hombre-naturaleza, pero también de lo que el medioambiente es. Por lo tanto, se considera de vital importancia, antes de analizar el campo de los conflictos socioambientales, brindar los elementos para definir tal concepto. El medioambiente remite, por principio, a un constructo histórico-social, es decir, a la naturaleza transformada por la acción humana a lo largo del tiempo, por lo que no solo incluye los sistemas bióticos y los ecosistemas, sino también las actividades del hombre. El medioambiente es, por lo tanto, «naturaleza humanizada, historizada, cargada de significados humanos $\gg$ (Aguilar $y$ Contreras, 2009: 268). Asimismo, «designa las relaciones de interdependencia que existen entre el hombre, las sociedades y los componentes físicos, químicos y bióticos del medio e integra también sus aspectos económicos, sociales y culturales $\gg$ (Aguilar y Contreras, 2009: 268).

Partiendo de estas características, parecería innecesario poner el prefijo socio a ambiental, pues su consustancialidad es más que evidente. Sin embargo, siguiendo los argumentos de Darcy Tetreault, Heliodoro Ochoa y Eduardo Hernández (2012: 15), vale la pena sostener la redundancia para recalcar la «dimensión social de los problemas ambientales $\gg$, la cual se distingue por sus diversas implicaciones económicas, políticas, culturales y simbólicas. De esta manera, reuniendo todos los elementos anteriores, los conflictos socioambientales pueden ser definidos como: procesos de disputa o antagonismo originados por la apreciación de un agravio surgido de la dimensión medioambiental. Dicho agravio se vincula a diversas prácticas o «lenguajes de valoración» (Paz, 2012: 39) que están vinculados no solo a la variable económica (como lo referente a la disponibilidad, explotación y acceso a los recursos naturales), sino también a las diferentes ramificaciones, igualmente importantes, del daño al ambiente como el deterioro de la salud (derivado de la polución y contaminación en todas sus formas), la destrucción del patrimonio cultural (la desaparición o menoscabo de infraestructuras, edificios, expresiones o lugares cargados de significados por efecto del aprovechamiento de algún recurso vital) o la afrenta a la dignidad e identidad de las personas cuando la cosificación del medioambiente, por parte de determinados actores, conlleva privación, discriminación, exclusión o la profundización de las desigualdades sociales. Por lo tanto, los conflictos socioambientales no son meras disputas por la propiedad de un recurso, ya que en ellos también se evidencia una oposición de cosmovisiones, discursos, prácticas, valoraciones y formas de entender el mundo. 
Es necesario problematizar más el punto anterior debido a que el actual entorno de fuertes contrastes socioeconómicos y la lógica especializada de las ciencias, tanto sociales como naturales, han generado que los conflictos socioambientales hayan sido estudiados sistemáticamente desde la lógica económica, es decir, el medioambiente como conjunto de recursos naturales. Lo anterior ha provocado que en muchas ocasiones las variables socioambientales, políticas, simbólicas y culturales cobren relevancia solo en relación con lo monetario o subordinadas con respecto a la satisfacción de las necesidades materiales e inmediatas (Fountaine, 2003 b: 28-29). Estos fundamentos teóricos han permitido el aumento de la influencia de las teorías de corte racionalista privilegiando con ello, entre otras cosas, un enfoque sobre las necesidades y los intereses de actores racionales (en el más estricto sentido del término) que desean acceder a recursos escasos o, como lo propone la llamada teoría de juegos, actores que tienen diferentes grados de probabilidad de participar en un juego (un conflicto socioambiental) dentro de un esquema simple de suma cero o ganador/ganador (Fountaine, 2003b: 29).

En otra vertiente, ese tipo de perspectivas teóricas han derivado en el surgimiento de lo que Tetrault et al. (2012:15) llaman los optimistas tecnológicos, refiriéndose a aquellos especialistas que suponen que todos los problemas relacionados con el medio ambiente se pueden solucionar mediante nuevas técnicas o implementos tecnológicos, obviando por lo tanto el resto de implicaciones socioculturales y políticas.

Es claro que todas esas formas de entender y de ofrecer soluciones sobre los conflictos socioambientales han contribuido positivamente al estado actual del debate. Sin embargo, de todo lo dicho se desprende que este tipo de problemáticas deben ser analizadas y explicadas en consideración de su complejidad, por lo que es necesaria una visión multidisciplinar o transdisciplinar que intente comprenderlos de manera integral.

\section{Lo histórico, lo estructural y lo global en los conflictos socioambientales}

En ese sentido, es necesario iniciar por concebir a los actuales conflictos socioambientales como procesos originados por y en un determinado contexto histórico. Al respecto, teniendo un particular interés en la situación de América Latina, no se puede decir que los conflictos socioambientales, como fenómenos sociológicos, sean recientes; ${ }^{2}$ sin embargo,

\footnotetext{
${ }^{2}$ Tal como lo explica David Carruthers (2008: 5), existe una larga historia de movilizaciones sociales en los países latinoamericanos que en muchos casos han tenido que ver con la defensa del medio ambiente. En especial, el autor refiere a los conflictos relacionados con las luchas por la tenencia de la tierra, las prácticas agrícolas y la defensa de determinadas tradiciones en conexión con la variable indígena.
} 
lo que sí se puede afirmar es que se han transformado debido al llamado proceso de globalización, que ha provocado, entre muchas cosas más, la profundización de las relaciones de dominio o dependencia que enfrentan los Estados latinoamericanos.

En efecto, hay una enorme convergencia entre investigadores de diferentes países que, respecto a los orígenes de los conflictos socioambientales, consideran el proceso de formación y desenvolvimiento de los Estados en América Latina como un elemento central. $\mathrm{Al}$ respecto, el pasado colonial de estos países los lleva a mantener una posición estructural subordinada a los centros dominantes, es decir, respecto a los países y zonas nucleares que acumulan o absorben un mayor porcentaje de los beneficios generados a nivel mundial (Composto y Navarro, 2014: 40), especialmente de aquellos producidos por las áreas periféricas. De esta manera, América Latina adquirió el rol histórico de exportadora de naturaleza en beneficio de los países industrializados y las grandes potencias emergentes (Svampa y Viale, 2014: 51). No obstante, un elemento importante que se debe recalcar es que las instituciones y los gobiernos latinoamericanos han aceptado, y muchas veces encomiado, esa posición subordinada que hoy en día va de la mano con una profundización de la mercantilización de la naturaleza (Svampa y Viale, 2014: 54). Así, no son pocos los casos en donde ha sido, y sigue siendo, justamente el Estado uno de los principales actores de dichos conflictos, precisamente porque ha optado por cooptar, hegemonizar, excluir y ordenar (Ortiz, 1999: 29).

Ahora bien, esta situación ha tomado un giro vertiginoso con lo que las ciencias sociales han comúnmente llamado el fin del Estado de bienestar, ya que la ideología de libre mercado y el reacomodo de las relaciones geopolíticas han ampliado, en el nivel macro, las asimetrías entre Estados y, a la vez, en el nivel micro, las desigualdades sociales y la brecha entre riqueza y pobreza. De esta manera, nuestros procesos históricos, a partir de los cuales existe un sinnúmero de analogías, muestran una serie de elementos estructurales caracterizados por la dependencia, la agudización del subdesarrollo, la marginación y el refuerzo de las condiciones de dominación (Guerrero, 1999: 44). Son justo estos escenarios los que vuelven factible la emergencia de conflictos de diversa índole, pero en especial aquellos que se relacionan con valores o recursos que son percibidos, en un sentido global, como esenciales.

Por supuesto que estas condiciones han afectado particularmente al medioambiente, ya que después de los procesos de industrialización de los países latinoamericanos, que dejaron evidencias claras de su deterioro, hoy se enfrentan condiciones mucho más profundas debido a la inserción de otros actores, especialmente empresariales y transnacionales, que están aprovechando la retracción del Estado (especialmente en Latinoamérica) 
$\mathrm{y}$, al respecto, las facilidades (producto de esas actuales condiciones de dominación simbólica entre Estados) y la relajación de la soberanía territorial, que han permitido, incluso en el sentido normativo, la legitimación del despojo. Este es un punto fundamental para entender lo que se está viviendo en la actualidad, pues las reglas se han acondicionado (o torcido) en aras de la «libertad del mercado» y el «acercamiento entre naciones», para que las transnacionales o diversas empresas exploten (o saqueen) legítimamente (es decir con aval de los Estados, e incluso ante la mirada complaciente de ciertas élites corporativas y políticas internacionales) los territorios sin importar el daño causado a las diferentes comunidades.

Para definir y explicar mejor este proceso sociológico, el estudio de los conflictos socioambientales en América Latina se ha apoyado en el concepto de acumulación por desposesión de David Harvey. Este refiere a una dinámica histórica, surgida con el arraigo y la profundización del capitalismo, la cual se caracteriza por el aumento de las desigualdades sociales como consecuencia de la liberalización mercantil (Harvey, 2004: 112). Respecto al medioambiente, existe un sinnúmero de elementos estructurales que ejemplifican lo mencionado, a decir: la privatización de la tierra y expulsión forzosa de las poblaciones campesinas; la conversión de diferentes formas de propiedad común o colectiva en derechos de propiedad exclusiva, y los procesos coloniales, neocoloniales e imperiales de apropiación de activos, en especial los recursos naturales, que han provocado la proliferación de la degradación ambiental (Harvey, 2004: 113-114).

No obstante, este proceso de acumulación por desposesión arraigado históricamente y determinante para el desenvolvimiento de los países latinoamericanos (en especial durante el siglo $\mathrm{xx}$ ) ha mostrado un agravamiento y una profundización con las crisis económicas globales y con lo que Composto y Navarro (2014:49) definen como la «ruptura del equilibrio fordista entre el capital y el trabajo», ya que la consecuente ola privatizadora permitió la mercantilización de servicios públicos, bienes comunes y relaciones sociales (Composto y Navarro, 2014: 49). Según estas autoras, dicho proceso ha significado la ampliación del rol geopolítico de América Latina y, a su vez, la revaloración de sus territorios y bienes naturales. En tal sentido, aseguran que se ha iniciado una nueva ofensiva extractivista $^{3}$ o un modelo de desarrollo neoextractivista que profundiza el despojo y la depen-

${ }^{3}$ Las autoras consideran el extractivismo como una modalidad de acumulación que, después de quinientos años, se ha diseminado de distintas formas por América Latina. Su característica principal es «la remoción de grandes volúmenes de bienes naturales no renovables para ser exportados al mercado internacional sin procesamientos previos significativos $\gg$ (Composto y Navarro, 2014: 51). 
dencia, en especial considerando los siguientes cuatro elementos: $a$ ) la aproximación hacia el umbral de agotamiento de bienes naturales no renovables; $b$ ) el desarrollo de técnicas de exploración y explotación más agresivas; c) la transformación de bienes naturales renovables en bienes naturales potencialmente no renovables, yd) la conversión de los bienes naturales en commodities, por lo que el lucro y la especulación han aumentado en forma exponencial (Composto y Navarro, 2014: 51).

Respecto del extractivismo y el neoextractivismo, es claro que existen diversas condiciones estructurales, históricas, económicas y sociopolíticas que son similares o compartidas por los países que integran América Latina. ${ }^{4}$ Sin embargo, es importante establecer que lo anterior no significa que no existan contrastes importantes. Sobre tal punto, Composto y Navarro (2014) consideran que en la actualidad los gobiernos de los países latinoamericanos son representativos de tres proyectos ideológico-políticos diferentes: $a$ ) el socialismo del siglo XX I o socialismo comunitario; $b$ ) el neoliberalismo armado, y $c$ ) el neodesarrollismo. Obviamente todos están conectados de una u otra forma con la profundización del neoliberalismo, pero guardan algunas disimilitudes que vale la pena establecer por lo menos de manera breve.

El primero de ellos (en el cual se puede identificar a Bolivia, Venezuela y Ecuador) es un proyecto popular que se fundamenta en las luchas y movimientos históricos, así como en su institucionalización dentro de gobiernos de izquierda que buscan, en teoría, pasar de una matriz colonial de Estado a una con carácter plurinacional (Composto y Navarro, 2014: 53). El segundo (del cual son representativos México, Colombia y Perú) representa una continuidad y profundización del modelo neoliberal mediante una recolonización política, económica y territorial a partir de la firma de tratados de libre comercio con Estados Unidos, así como de la mayor presencia de los correspondientes ejércitos con el fin de desactivar las resistencias e imponer el orden necesario para cumplir con los designios del Banco Mundial (в м) y el Fondo Monetario Internacional (F M I) (Composto y Navarro, 2014: 53). Por último, el tercero (cuyos exponentes son, por ejemplo, Brasil y Argentina) representa un modelo democrático de participación controlada que, en el papel, supuso un desmantelamiento de ciertas orientaciones neoliberales, pero que en la realidad no ha evitado su continuidad (a partir de, por ejemplo, la estructura productiva y la elección

${ }^{4}$ Comparten no solo la instalación de un modelo económico que se basa en la extracción intensiva de bienes naturales, sino también de un modelo ideológico y político que «refleja el poder del centro frente a las regiones» y el de la «inversión privada frente a las instituciones colectivas» (Composto y Navarro, 2014:52). 
de socios económicos), por lo que no se ha traducido en transformaciones sustanciales (Composto y Navarro, 2014: 53). ${ }^{5}$

Sin embargo, el punto importante que se debe destacar es que, a la par de esas tendencias, modelos y proyectos aparentemente globales ( $y$ con amplias consecuencias para América Latina), se han originado una serie de respuestas de diversa índole y desde diversas trincheras que desean no solo posicionarse en contra de esas tendencias nocivas, sino también denunciar los agravios ante la opinión pública, medios de comunicación y, en algunos casos, frente a la crítica internacional, con el fin de hacer partícipes, movilizar o informar al mayor número de personas acerca de lo que ocurre en determinados rincones del mundo. En otras palabras, contribuir, en forma paralela a los conflictos y a las correspondientes reivindicaciones, a la formación de una conciencia global que implica la aceptación de que lo ocurre en un determinado lugar del planeta, por más pequeño que sea, puede estarse reproduciendo en otro sitio y que en lo concerniente al medioambiente sus efectos repercuten en todos.

En el caso específico de las movilizaciones en contra del deterioro del medioambiente provocado por la profundización del neoliberalismo y del neoextractivismo, su origen se dio a partir de los años setenta, década en que emerge una ideología contrahegemónica respecto al deterioro ambiental y sus implicaciones a nivel global. Fue paradigmático en Estados Unidos ${ }^{6}$ y Europa, donde surgieron dichos movimientos como crítica no solo a los visibles daños al medioambiente por efectos de la sobreexplotación, sino también por la relación intrínseca entre estos y el reordenamiento de las políticas internacionales que, en

${ }^{5}$ Sobre estos modelos vale la pena decir que no se encuentran en estado puro (aunque se considera a uno como el predominante en cada país) ya que, como lo mencionan las autoras de referencia, pueden existir interrelaciones importantes. $\mathrm{Al}$ respecto, las autoras consideran que Bolivia es un buen ejemplo de lo anterior, ya que si bien hacia el exterior mantiene una retórica de ecocomunitarismo y, a la vez, de denuncia sobre los efectos globales del cambio climático, hacia el interior muestra las contradicciones de los proyectos en América Latina al permitir la profundización de las actividades extractivas, en clara consonancia con el neodesarrollismo (Composto y Navarro, 2014: 56).

${ }^{6}$ Los movimientos sociales en favor de la conservación del medioambiente en América Latina cuentan con raíces históricas muy profundas y, por ello, contienen características propias que no pueden ser analizadas con las categorías creadas para explicar las movilizaciones en Estados Unidos o Europa. Sin embargo, la llamada justicia ambiental ha sido un modelo retomado de experiencias de Estados Unidos para entender lo que ocurre en muchos otros países, sin que esto signifique un trasplante simple de categorías (Carruthers, 2008: 13). 
sus múltiples embates, cercenan los derechos de muchas comunidades en todo el planeta, pero en especial en aquellos países que han guardado un estado de dependencia.

Este nuevo enfoque respecto al deterioro del medioambiente ha permitido que las legislaciones nacionales e internacionales contengan un mayor reconocimiento de las contradicciones y de los derechos de las poblaciones afectadas (Fontaine, 2013a: 505), es decir, del medioambiente como un derecho humano irrenunciable y clave para el bienestar de todas las personas. Sin embargo, la realidad demuestra que en muchas ocasiones se ha vuelto parte de un discurso que no se traduce en reglas claras (igualitarias o que incluso valoren la posición estructural de los posibles afectados), pero especialmente en prácticas concretas que se encaminen a limitar el poder de determinados actores, como los propios Estados y, así, el medioambiente no sea visto como un objeto que puede ser cedido o adjudicado bajo presiones o estímulos económicos o políticos.

Siguiendo el argumento, es necesario decir que en estos procesos señalados y vividos en América Latina respecto al medio ambiente se evidencia una contradicción de fondo en la posición de los Estados, que sin lugar a dudas pone de manifiesto los actuales dilemas o paradojas de la globalización y respecto del actual ordenamiento de las relaciones geopolíticas. En efecto, por principio, el paradigma de libre mercado promovido por determinados países, empresas y élites políticas impulsa una ideología que pretende la apertura de la competencia económica como supuesto mecanismo de redistribución de la riqueza ${ }^{7}$ cuando, por el contrario, ha aumentado la exclusión social y, en el caso del medio ambiente, la aceleración de su deterioro precisamente porque competir se ha traducido, en muchos casos, en sobreexplotar o despojar.

Sin embargo, a esta primera contradicción, por demás evidente, se le encadena una más bien latente, subyacente, que surge, en efecto, del actual estado de las relaciones de

${ }^{7}$ Proceso que, en teoría, requiere la retracción del Estado o el fin del Estado de bienestar debido a que este, cuando tomó medidas para proteger sus mercados internos y a sus productores nacionales, se convirtió en un obstáculo para la apertura comercial y la competencia. De ahí que el libre mercado o la corriente neoliberal privilegia una ideología en la que todos aquellos que desean competir lo pueden hacer mediante sus propias capacidades, lo cual no solo supone la simetría de fuerzas entre competidores (algo por demás irreal), sino también la menor necesidad de un Estado intervencionista. De ahí que se ha impulsado la idea de un Estado mediador, es decir, que solo tenga el papel de facilitador entre los competidores y la mano equilibrante y justa del mercado. Sin embargo, más allá de la lejanía de estos supuestos con respecto a la realidad, lo anterior ha permitido, colateralmente, el encubrimiento de la incapacidad de muchos Estados (como los latinoamericanos) para cumplir con sus tareas y responsabilidades primordiales. 
fuerza entre Estados, que refiere a la creación e impulso de una agenda internacional sobre medioambiente y respecto de determinadas soluciones legítimas a su deterioro. En otras palabras, han sido varios de esos países (así como actores provenientes de esas mismas élites políticas y empresariales que, al día de hoy, se autoetiquetan como socialmente responsables), que han promovido de diversas formas la ideología de libre mercado, los que de igual manera han participado en la delimitación de los problemas medioambientales y las mejores estrategias para encararlos.

A este tipo de procesos sociopolíticos Joseph Gusfield (2014) los ha analizado a partir del concepto de propiedad de los problemas públicos. Este refiere a que en todo problema que adquiere la dimensión de público existe un determinado número de actores, grupos, élites, instituciones, empresas, etc., que tienen la capacidad y el poder de definirlo como problema, ofrecer las mejores soluciones y, por ende, de desestimar otras opciones; resumiendo en una frase, se apropian de los problemas públicos. Así, los problemas medioambientales han ido pasando por este mismo proceso; pero debido a su magnitud e impactos, que es a escala planetaria, su apropiación ha implicado la intervención de actores con capacidad de incidir en los escenarios globales (como sería el caso de algunos Estados de América del Norte y Europa Occidental).

Es justamente este proceso de apropiación el que plantea una paradoja muy importante, aunque poco visible ya que, respecto al medioambiente, los Estados latinoamericanos enfrentan doble presión. Por un lado, aquella que les exige abrirse al concierto del mercado global (muchas veces en detrimento de sus territorios y poblaciones) y, por otro, aquella que les pide instrumentar determinadas acciones o medidas para proteger el medio ambiente. Dos caras de una misma moneda, con un mismo origen y que refieren a mecanismos similares de incentivos y coerción: si creas las condiciones (económicas, políticas, territoriales, infraestructurales e incluso socioculturales) necesarias para la apertura comercial no solo aportarás al estrechamiento de vínculos con los Estados, élites y empresas que encabezan los procesos, sino también accederás a recursos internacionales, provenientes de esos mismos países, del ғ м I о el в м, para continuar con esas reformas estructurales. Similar escenario o esquema plantean las problemáticas medioambientales, lo que da como resultado un estrangulamiento de los Estados dependientes (como los latinoamericanos), ya que de no ajustarse a dichos preceptos no solo dejarían de acceder a los recursos económicos, sino también a los beneficios de ser parte de un sistema global creado por y para los «ganadores $»$.

Lo anterior representa un camino estrecho, es decir, con un mínimo margen de maniobra, en el cual se les pide a los países que hermanen el cuidado del medioambiente con 
la apertura comercial. Este ha sido justificado, habilitado y ampliamente socializado a partir de un discurso, a veces muy convincente, que pretende la imposición de determinadas categorías y conceptos (Liffman, 2009: 202). Al respecto, la mencionada brecha está representada, y fielmente depositada, en la idea de desarrollo sustentable, ya que en efecto es una frase muy utilizada para señalar el ideal de productividad económica y de conservación ambiental. Sin embargo, sin negar en absoluto los provechosos esfuerzos realizados por diversos activistas, profesionistas y académicos para desarrollar las estrategias o mecanismos que permitan la materialización del concepto, la realidad muestra que ha sido originado y utilizado, en muchas ocasiones, como una eventual táctica política operada a partir de todo un lenguaje construido para diseminar una ideología que, más allá de explicitar y exaltar las buenas intenciones, oculta un proceso de legitimación de las paradojas (y coacciones) globales y respecto de las dependencias y asimetrías en igual escala.

En efecto, las nociones de desarrollo sustentable y de economía verde se han convertido en partes integrantes de un discurso hegemónico que ha quedado legitimado en una parte del derecho ambiental y en las declaratorias internacionales (Svampa y Viale, 2014: 45-48). Respecto al desarrollo sustentable, el orden de los conceptos no es algo irrelevante, ya que el poner primero al desarrollo significa, en términos de ese discurso hegemónico, dar mayor importancia a la valoración económica de las cosas y de las relaciones y la búsqueda del crecimiento, en esos mismos términos, como finalidad última de los Estados. Así, «la sustentabilidad se supeditó al desarrollo y la protección de la naturaleza al fetiche del crecimiento económico infinito como solución y regulación de las sociedades humanas» (Svampa y Viale, 2014: 50).

No obstante, más allá de que estas presiones y condiciones externas son muy reales para los casos latinoamericanos (ya que existe un sinnúmero de ejemplos que pueden servir como verificación del proceso), es necesario decir que, sumado a ese clima internacional adverso, los Estados de nuestros países han guardado una posición pasiva ( $\mathrm{y}$ a veces sumisa) ante tales coacciones, y no solo eso, pues también se han convertido en infinidad de casos en los principales implementadores o legitimadores de acciones contrarias al medioambiente y, a la vez, al bienestar o salvaguarda de sus comunidades conformantes. En otras palabras, el clima político-económico internacional y las crecientes asimetrías entre Estados en el escenario geopolítico global no explican (ni justifican) por completo lo que ha sucedido con respecto al deterioro del medioambiente en los países de América Latina. En efecto, es imposible negar la existencia de una serie de factores internos, como la inconsistente organización política e institucional, la opaca definición territorial y la consecuente tenencia de la tierra, la actual presión sobre las zonas rurales, la inserción de las 
lógicas espaciales del narcotráfico y, en general, el desenvolvimiento histórico de la relación entre Estado y sociedad, que han incidido con mucha fuerza en el deterioro del medioambiente en cada país.

En este sentido, no es posible olvidar las cualidades autoritarias de los regímenes latinoamericanos que, bajo la aceptación y el total convencimiento de las pautas de desarrollo impulsadas, provocaron o permitieron la destrucción del medioambiente en diversos rincones. Asimismo, tampoco podemos dejar de lado, en estos mismos escenarios internos, la poca o nula tolerancia al disenso y la crítica, la falta de diálogo abierto respecto a los principales problemas que enfrenta cada país, la escasa participación de la población en la toma de decisiones (Quintana, 2008: 6) y los efectos nocivos de la corrupción, ya que en muchas ocasiones implican severos daños al medioambiente.

Es justo en la convergencia de todas estas condiciones internacionales, de los procesos históricos y de las diferentes tribulaciones internas de cada país latinoamericano que podemos comprender la complejidad de los conflictos socioambientales y su agudización en las últimas décadas. Asimismo, de la insuficiencia o tergiversación de las estructuras legales, administrativas e institucionales en general para lidiar con estos problemas, considerando que los agravios crecen y faltan las respuestas serias o coherentes. No obstante, el resultado más importante, en términos de análisis sociológico, de todo este panorama general y de la interconexión de variables que evidencia, es la posibilidad brindada para entender la magnitud del problema que enfrentan las reivindicaciones y los movimientos medioambientales.

En efecto, una perspectiva holística sobre los conflictos socioambientales permite reafirmar que su conformación y desarrollo no pueden ser reducidos a un esquema dicotómico (А contra в) impulsado exclusivamente por intereses materiales, ya que esto brinda una explicación muy sesgada de los trasfondos intervinientes. En esa tesitura, los conflictos socioambientales representan un escenario perfecto o ideal, sin dejar de ratificar el sentido sociológico de tales palabras, para observar las contradicciones y paradojas de un sistema en el cual quedan vinculados lo coyuntural o lo inmediato con lo estructural y lo histórico, para develar la profundidad de las implicaciones simbólicas ${ }^{8}$ e ideológicas del enfrenta-

${ }^{8}$ En el sentido expresado por Pierre Bourdieu (2009), es decir, simbólico en términos de aquel capital o poder que, en ocasiones mal definido como ineficaz e inútil, refiere al honor, prestigio o legitimidad de determinadas personas, colectivos o instituciones que lo acumulan para provocar efectos concretos y materiales. Respecto al problema que este artículo trata, lo simbólico refiere a la naturalización de las relaciones de poder asimétricas y de las desigualdades que han permitido la difusión y el enraizamiento 
miento asimétrico y muchas veces coercitivo entre lo global y lo local. En otras palabras, son el reflejo fidedigno de las luchas emprendidas desde abajo para contrarrestar los deseos de dominación de unos cuantos y para demostrar que la verticalidad no puede ser total o que incluso es posible utilizar las propias herramientas de la globalización en contra de esas tendencias, es decir, lo global como ventana de oportunidad; un punto al cual se regresará un poco más adelante.

\section{Conflictos socioambientales, poder y territorio}

Todos los argumentos y reflexiones anteriores nos llevan a afirmar que los conflictos socioambientales tienen una fuerte impronta política, pero también, y aún más importante, una clara estructuración a partir de relaciones de poder (todas ellas multiformes y a la vez caracterizadas por su movilidad entre escalas). Así, el concepto de poder representa un elemento central para entender la complejidad de este tipo de fenómenos, pues en él recaen diversos enfoques, escuelas, debates y bagajes provenientes de prácticamente todas las ramas de las ciencias sociales. Es decir, en la actualidad se utiliza como una herramienta heurística y transdisciplinar que permite una perspectiva analítica sumamente rica, en especial cuando lo que se pretende es evidenciar en una frase el origen, la magnitud, el trasfondo y las consecuencias de toda oposición entre actores respecto a un determinado hecho social.

Por lo dicho, se reafirma que hablar de poder significa no darle mayor peso a priori a una determinada variable estructural, sino que al enlazar una enorme heterogeneidad de procesos, variables, intereses, perspectivas, valoraciones y prácticas, cruza y enlaza diferentes campos desde el económico-político hasta el simbólico y cultural. Esto conlleva como ventaja para el estudio de los conflictos socioambientales la posibilidad de entender este tipo de fenómenos como un choque que va más allá de las racionalidades materialistas, ya que involucran formas contrapuestas de entender el mundo, y en especial al medioambiente si se considera su amplio espectro de conceptualizaciones, es decir, desde su definición básica como conjunto de recursos naturales hasta la de espacio de vida.

Debido a lo anterior, el poder es un concepto que se ha definido de muchas maneras y de acuerdo con diferentes objetos de estudio, lo cual lo ha llevado a una polisemia que ha sido objeto de muy diversos debates. Aun así, la gran mayoría de ellos coinciden en que

de la definición del medioambiente como un conjunto de recursos naturales, es decir, como un objeto. Asimismo, la legitimación de un orden a escala global que ha hecho del dinero, de la acumulación a ultranza y de la competencia sus pilares ideológicos principales. 
el poder es un «elemento omnipresente y constitutivo en todas las relaciones sociales» (Preciado, 2001: 175) o, dicho de otra manera, «cualquier construcción de la realidad es un instrumento de poder desde los orígenes del hombre» (Raffestin, 2013: 175), por lo que contiene un sinfín de expresiones y múltiples rostros. Asimismo, hay un acuerdo, más o menos generalizado, acerca de que el poder no es algo que se posee, sino más bien un conjunto de prácticas que «se despliegan estructurando el campo de acciones eventuales de los otros» (Di Giminiani, Aedo y Loera, 2016: 30). Finalmente, vale la pena decir, respecto al mencionado concepto, que puede representar una fuerza no solo destructiva o coercitiva, sino también creadora, crítica, revolucionaria y, por qué no, potencialmente transformadora de la realidad imperante.

Sin embargo, en consonancia con las metas de este artículo, es necesario delimitar de mejor manera el término con el fin de comprender sus aportes al campo de los conflictos socioambientales. Para cumplir tal objetivo es necesario vincular el poder con el territorio, pero comprendiendo a este último no como una simple porción de superficie, sino más bien como una dimensión de lo social, un espacio en el cual se entrelazan «trabajo, energía e información y que, en consecuencia, revela relaciones marcadas por el poder» (Raffestin, 2013: 173). Este punto desea hacer explícito que toda relación de poder conlleva una dimensión o expresión espacio territorial y, a su vez, todo vínculo entre sociedad y territorio representa una forma de poder. Claro está que en el caso de los conflictos socioambientales esto es aún más evidente, ya que poder y territorio son dos caras de una misma moneda.

Siguiendo el argumento, lo que los conflictos socioambientales revelan es el choque o la contraposición entre territorialidades incompatibles. Entendiendo la territorialidad como un reflejo de «la multidimensionalidad de la vivencia territorial por parte de los miembros de una colectividad y por las sociedades en general» (Raffestin, 2013: 189). Por lo tanto, el agravio que origina un conflicto socioambiental refiere a la oposición entre concepciones territoriales (o territorializadas) y, aún más importante, a la transgresión de determinados límites ${ }^{9}$ que son percibidos como afrenta a un espacio vital. Además, es necesario recalcar que esta territorialidad se encuentra especialmente tensada en los actuales escenarios mundiales pues, como ya se mencionó, no se trata solo de sobreexplotación y

\footnotetext{
${ }^{9}$ En este caso «límite» no indica — por lo menos no exclusivamente- el trazado de una línea imaginaria que queda formalmente contenida en un mapa (que referiría en todo caso a aquellos correspondientes al Estado), sino más concretamente a la delimitación de la vivencia territorial que, ante un agravio, se activa para señalar una transgresión. Por lo tanto, es un límite moral, histórico tradicional, ideológico y evocado.
} 
de un nuevo modelo de competencia económico-comercial global, sino también de toda una ideología, con sus consecuentes prácticas hegemónicas que respecto al medioambiente tiende a la exclusión o al despojo de las comunidades y, por ello, es atentatorio de su sentido de identidad espacial (Raffestin, 2013: 192).

Esta relación intrínseca entre los conflictos socioambientales, el territorio y el poder ha sido estudiada por diversas ramas de las ciencias sociales, pues justamente se ha comprendido que este tipo de problemáticas evidencian una serie de condiciones estructurales que no pueden obviarse si se pretende comprender su profundidad y sus consecuencias. Es así que tanto la antropología política como la sociología política, pero especialmente la geografía política, la geografía del poder y la ecología política han ampliado los debates al respecto buscando, a partir del refinamiento teórico, conceptual, epistemológico y metodológico, mejores estructuras analíticas para explicar esa compleja realidad. Sin embargo, existe una coincidencia entre estos campos que va más allá de las metas estrictamente académicas, pues en la identificación de los actores inmiscuidos en un conflicto socioambiental, así como de la fuerza relativa de estos y de las relaciones estructurales de poder (Brenner y Hüttl, 2009: 325), existe un explícito reconocimiento y una denuncia de las asimetrías, desigualdades y agravios, por lo que también se cumple con una importante función político-ideológica en términos de la defensa de los derechos de las comunidades perjudicadas y de la necesidad de generar conciencia y nuevas prácticas respecto al cuidado del medioambiente.

Hablando especialmente del desarrollo de estos temas en América Latina, hay un sinnúmero de investigaciones que han señalado las contradicciones del sistema y sus severas implicaciones para el medioambiente. Al respecto, son muchos los trabajos que han analizado y documentado la presión que se ha ejercido sobre recursos tales como los yacimientos de minerales o de petróleo, ${ }^{10}$ el agua, el gas natural y los bosques, selvas, así como las respuestas, luchas, estrategias y recursos de las comunidades o colectivos que se asumen como afectados y se organizan para resistir tales embates del neoliberalismo y la globalización.

\footnotetext{
${ }^{10}$ Respecto a este punto, es necesario mencionar que, hablando de neoextractivismo, en América Latina la actividad más prolífera es la minería (Toledo, Garrido y Barrera, 2014: 119). Sobre tal punto, empresas de Inglaterra, Canadá, China, Japón y otros países han realizado inversiones millonarias en los nuestros con el fin de extraer diversos tipos de materiales. Algunos casos emblemáticos, y que han significado conflictos socioambientales importantes, pueden ser consultados en Toledo, Garrido y Barrera (2014) y en Arsel, Mena, Pellegrini y Radhuber (2014).
} 
Sobre este último punto es relevante establecer que varias de tales movilizaciones $\mathrm{u}$ organizaciones han logrado globalizar sus luchas y, en ese sentido, construir nuevas formas de entender la acción social y su consecuente territorialidad. En concreto, han conseguido arropar sus reivindicaciones mediante la construcción de alianzas globales de afectados e interesados en los temas medioambientales. Redes que no solo actúen en defensa de una determinada reivindicación, sino también en favor de la creación de una conciencia general respecto al deterioro del medioambiente y, en igual sentido, de la ideología neoliberal que avala, impulsa y legitima tales daños en aras de la competencia, el libre mercado y la acumulación.

A la par de este proceso, es necesario entender esas reivindicaciones en sus prácticas y discursos como creadoras de nuevas territorialidades. En efecto, con la transnacionalización de sus luchas, las comunidades, grupos o colectivos en defensa del medioambiente se convierten en lo que Claude Raffestin llama «actores sintagmáticos» que están produciendo territorio (2013:183); en este caso uno muy particular, por efecto de la socialización de una posición contrahegemónica, para ganar espacios de vinculación emocional, pero también político-ideológica con una problemática que ya no puede ser entendida como aislada, limitada y coyuntural, sino más bien con alcances más generales y fundamentada en condiciones estructurales e históricas arraigadas.

A esta dinámica se suma el uso de las redes virtuales, que han dislocado la anterior lógica de contigüidad o cercanía territorial como un elemento necesario para difundir una idea, demostrando con ello que el territorio, como construcción social, se ha vuelto mucho más flexible. En este sentido, los movimientos en defensa del medioambiente han logrado evidenciar la capacidad de los instrumentos de la globalización para actuar en ambos sentidos, es decir, no solo como diseminadores y legitimadores de asimetrías y jerarquías, sino también como herramientas para la resistencia y «la construcción de imaginarios geopolíticos alternativos» (Preciado, 2011:175).

\section{A manera de conclusión}

No fue objeto de este artículo sugerir, ni implícita ni explícitamente, que no ha habido ningún esfuerzo destacable y redituable de parte de los Estados latinoamericanos por frenar o revertir los daños causados al medioambiente. Sin embargo, sí fue una meta importante señalar y describir una serie de condiciones (estructurales e históricas muchas de ellas) que han evitado que esos esfuerzos sean lo suficientemente significativos como para que hayan modificado en forma importante las asimetrías que han dado origen a los conflictos socioambientales de las últimas décadas. Sobre esa tarea aún falta mucho por hacer y, aun- 
que el panorama no parece muy favorable, las crecientes movilizaciones y reivindicaciones en favor del medio ambiente exhiben algunas opciones para transformar los escenarios actuales.

Ahora bien, como se dijo al principio, el conflicto es un fenómeno consustancial a lo social, por lo que se necesita, bajo los argumentos vertidos en este artículo, crear cada vez mejores herramientas analíticas para comprenderlo y explicarlo en toda su significación sociológica. Sin embargo, es necesario apuntar dos aspectos. El primero es que, más allá de la naturalización de la consustancialidad del conflicto respecto a lo social, sus causas deben ser sujetas a mayores críticas, en especial si conllevan la aceptación o legitimación del crecimiento de las desigualdades sociales, las jerarquías y la dominación. En el caso del medioambiente no se deben normalizar la sobreexplotación, la exclusión y el despojo, ya que esto no solo atenta contra los derechos, sentidos y territorialidades de las comunidades afectadas, sino también de la salvaguarda de la vida humana si consideramos que lo que está en juego, visto desde una perspectiva radical mas no irreal, es la sobrevivencia de la especie.

El segundo refiere al potencial que tiene el conflicto para transformar la realidad imperante. En este sentido, las luchas en defensa del medioambiente han hecho del conflicto su motor de cambio, lo cual está ligado a la exposición pública de las contradicciones del sistema, así como a la socialización de una ideología contrahegemónica. Estos elementos no solo son fundamentales para darles continuidad a las movilizaciones a favor del medioambiente, sino también para la construcción de una conciencia global que realmente logre confrontar las tendencias internacionales y fomentar la disminución del deterioro. En este sentido, el conflicto, como productor de alternativas, revela la emergencia de nuevos actores que participan desde diversas trincheras en la construcción de un mundo diferente.

Finalmente, se desea recalcar que una de las principales metas de este documento es aportar, por lo menos desde una perspectiva general, a la diseminación, por un lado, de algunos de los principales debates y avances académicos respecto a los conflictos socioambientales; pero también, por otro lado, un posicionamiento frente al deterioro del medioambiente y de las estructuras de poder actuantes. Esto último es considerado de vital importancia, ya que los progresos por la ciencias sociales no solo deben traducirse en la generación de nuevos conocimientos teóricos, conceptuales y metodológicos respecto a la realidad social, sino también en la colaboración activa, que para el caso de los conflictos socioambientales significa la participación directa en la conservación del medioambiente y en la construcción de sociedades más justas $\diamond$ 
Referencias

Aguilar, M. y Contreras, C. (2009). La geografía ambiental. Orígenes, ámbito de estudio y alcances. En Chávez, M., González, O. y Ventura, M. (eds.), Geografía humana y ciencias sociales. Una relación reexaminada (pp. 261-296). Zamora: El Colegio de Michoacán.

Arsel, M., Mena, C., Pellegrini, L. y Radhuber, E. (2014). Property rights, nationalization and extractive industries in Bolivia and Ecuador. En Bavinck, M., Pellegrini, L. y Mostert, E. (eds.), Conflicts over natural resources in the global South - conceptual approaches. London: C R C Press.

Bourdieu, P. (2009). El sentido práctico. Buenos Aires: Siglo X X I Editores.

Brenner, L. y Hüttl, H. (2009). Ecología política. Un análisis geográfico de conflictos en un «medio ambiente politizado». Presentado con base en el ejemplo de la Reserva de la Biosfera Sian Ka’an, Quintana Roo. En Chávez, M., González, O. y Ventura, M. (eds.), Geografía humana y ciencias sociales. Una relación reexaminada (pp. 317-347). Zamora: El Colegio de Michoacán.

Carruthers, D. (2008). Introduction. Popular environmentalism and social justice in Latin America. En Carruthers, D. (ed.), Environmental justice in Latin America. Problems, promise, and practice. London: The Miт Press.

Composto, C. y Navarro, M. (2014). Claves de lectura para comprender el despojo y las luchas por los bienes comunes naturales en América Latina. En Composto, C. y Navarro, M. (comps.), Territorios en disputa. Despojo capitalista, luchas en defensa de los bienes comunes naturales y alternativas emancipatorias para América Latina. Ciudad de México: Bajo Tierra Ediciones.

Di Giminiani, P., Aedo, A. y Loera, J. (2016). Ecopolíticas globales. Medioambiente, bienestar y poder. Santiago de Chile: Hueders.

Fontaine, G. (2003a). Enfoques conceptuales y metodológicos para una sociología de los conflictos ambientales. En Cárdenas, M. y Rodríguez, M. (eds.), Guerra, sociedad y medio ambiente. Bogotá: Foro Nacional Ambiental.

Fontaine, G. (2003b). El precio del petróleo. Conflictos socioambientales y gobernabilidad en la Región Amazónica. Quito: F L A C s o sede Ecuador, Instituto Francés de Estudios Andinos.

Guerrero, P. (1999). Aproximaciones conceptuales y metodológicas al conflicto social. En Ortiz, P. (comp.), Comunidades y conflictos socioambientales: experiencias y desafíos en América Latina. Quito: Ediciones UPS, A BYA-YALA.

Gusfield, J. (2014). La cultura de los problemas públicos. El mito del conductor alcoholizado versus la sociedad inocente. Argentina: Siglo x x I Editores.

Harvey, D. (2004). El nuevo imperialismo. Acumulación por desposesión. Socialist Register 40, 99129.

Liffman, P. (2009). Territorialidad discursiva. Lenguaje, poder y geografía. En Chávez, M., Gon- 
zález, O. y Ventura, M. (eds.), Geografía humana y ciencias sociales. Una relación reexaminada. Zamora: El Colegio de Michoacán.

Molina, B. y Muñoz, F. (2004). Manual de paz y conflicto. Granada: Eirene, Universidad de Granada.

Mouffe, C. (1999). El retorno de lo político. Comunidad, ciudadanía, pluralismo, democracia radical. Barcelona: Paidós Ibérica.

Munévar, C., González, L. y Henao, A. (2016). Conflictos socioambientales: entre la legitimidad normativa y las legitimidades sociales. Caso mina La Colosa, Cajamarca (Tolima, Colombia). Revista Luna Azul, 44, 165-176.

Ortiz, P. (1999). Apuntes teórico conceptuales para el diseño de una propuesta metodológica de manejo de conflictos socioambientales a través de la forestería comunitaria. En Ortiz, P. (comp.), Comunidades y conflictos socioambientales: experiencias y desafíos en América Latina. Quito: Ediciones UPS, ABYA-YALA.

Paz, M. (2012). Deterioro y resistencias. Conflictos socioambientales en México. En Tetreault, D., Ochoa, H. y Hernández, E. (coords.), Conflictos socioambientales y alternativas de la sociedad civil. Tlaquepaque: I T E s o.

Paz, M. y Risdell, N. (2014). Conflictos, conflictividades y movilizaciones socioambientales en México: problemas comunes lecturas diversas. Ciudad de México: U N A M, Miguel Ángel Porrúa.

Preciado, J. (2011). Geopolítica crítica francesa: contribuciones a la geografía del poder y a la geografía electoral. En Capron, G., Icazuriaga Montes, C., Levi, S., Ribera Carbó, E. y Thiébaut, V. (eds.), La geografía contemporánea y Elisée Reclus. Zamora: El Colegio de Michoacán, c I e S A S, Instituto Mora.

Quintana, A. (2008). El conflicto socioambiental y estrategias de manejo. Diplomado plan de ordenación y manejo de la cuenca del río Salitre.

Raffestin, C. (2013). Por una geografía del poder. Zamora: El Colegio de Michoacán, Fideicomiso Felipe Teixidor y Monserrat Alfau de Teixidor.

Silva, G. (2008). La teoría del conflicto. Un marco teórico necesario. Prolegómenos. Derechos y Valores, XI (22), 29-43.

Stamm, C. y Aliste, E. (2014). El aporte de un enfoque territorial al estudio de los conflictos socioambientales. Faro Fractal, 2 (20), 66-78.

Svampa, M. y Viale, E. (2014). Maldesarrollo. La Argentina del extractivismo y el despojo. Buenos Aires: Katz Editores.

Tetreault, D., Ochoa, H. y Hernández, E. (2012). Introducción. En Tetreault, D., Ochoa, H. y Hernández, E. (coords.), Conflictos socioambientales y alternativas de la sociedad civil. Tlaquepaque: ITESO. 
CARTA ECONÓMICA REGIONAL |ISSN 0187-7674|AÑO 30|NÚM. 122 |JULIO-DICIEMBRE 2018|pp.7-30

Toledo, V., Garrido, D. y Barrera, N. (2014). Conflictos socioambientales, resistencias ciudadanas y violencia neoliberal en México. Ecología Política Cuadernos de debate Internacional, 46(41), 115-124.

Walter, M. (2009). Conflictos ambientales, socioambientales, ecológico distributivos, de contenido ambiental... Reflexionando sobre enfoques y definiciones. Boletín E C O s, 6, 1-10. 